\title{
Assessment of Knowledge and Practices of Pregnant Women regarding Hyperemesis
}

\section{Gravidarum}

\author{
Asmaa Sobhi Ahmed Elabasi ${ }^{1}$, Samia Abd-Elhakeem Hasneen Aboud ${ }^{2}$, Somaya Ouda Abd- \\ EImoniem $^{3}$ and Ola Abd-Elwahab Afifi Araby ${ }^{4}$
}

(1) Nursing specialist at Sirs Ellian Hospital, Egypt, (2) Professor of Obstetrics and Gynecological Health Nursing, Faculty of Nursing, Benha University, Egypt, (3) Assistant Professor of Obstetrics and Gynecological Health Nursing, Faculty of Nursing, Benha University, Egypt, (4) Lecturer of Obstetrics and Gynecological Health Nursing, Faculty of Nursing, Benha University, Egypt

\section{Abstract}

Background: Hyperemesis gravidarum is a high disorder characterized by ongoing severe nausea and vomiting affects $0.3-3 \%$ of women during pregnancy. Hyperemesis gravidarum badly affected the general health condition of pregnant women. Aim of study: Was to assess knowledge and practices of pregnant women regarding hyperemesis gravidarum. Study design: A descriptive study was utilized to conduct this study. Setting: This study was conducted at Obstetrics and Gynecological inpatient department and outpatient clinic at Benha University hospital. Sample: A purposive sample was used 50 pregnant women suffer from hyperemesis gravidaurm were admitted to the previous setting for eight months. Tools of data collection: Data were collected by using one tool: A structuredinterviewing questionnaire sheet which consisted of three parts, part I: Socio-demographic data, part II: Knowledge assessment sheet and part III: Maternal health practices questionnaire. Results: There was less than two-thirds of the studied women had poor knowledge regarding hyperemesis gravidarum; while less than one-third of them had good knowledge. Regarding to healthy practices of mothers, less than three-quarters of mothers had unsatisfactory healthy practices and less than one-third of them had satisfactory healthy practices regarding hyperemesis gravidaurm. Conclusion: There was a highly positive statistical correlation between total knowledge and total practices regarding hyperemesis gravidaurm. Recommendations: Designing, implementing and distributing guidelines for hyperemesis gravidarum through antenatal clinic during initial visit of the pregnant women.

Key words: Hyperemesis gravidaurm, Knowledge, Practices.

\section{Introduction}

Hyperemesis Gravidarum ( $\mathrm{HG})$ is the strongest form of nausea and vomiting in pregnancy, defined as unrelenting nausea and excessive vomiting initiated before the 22nd week. The incidence of hospitalization for $\mathrm{HG}$ is $0.3-3 \%$ of all pregnancies among all pregnancies and is the most common cause of hospital admission in the first trimester (Farg and Hassan, 2019).

The clinical picture and diagnosis of $\mathrm{HG}$ including these signs ptyalism, fatigue, weakness and dizziness are frequent symptoms associated with $\mathrm{HG}$, whilst rare symptoms also include hyperolfaction, dysgeusia, decreased gustatory discernment, sleep disturbance, depression, anxiety, irritability and mood changes. The diagnostic criteria of $\mathrm{HG}$ include nausea and vomiting more than three times per day, the detection of ketones in the urine or acetone in the blood, and weight loss greater than $5 \%$ of pre pregnancy body weight with dehydration, alkalosis from loss of hydrochloric 
acid, hypokalemia, ketosis and acidosis from starvation (Kloter, et al, 2019).

In relation to risk factors of $\mathrm{HG}$, hyperemesis patients commonly have multiple pregnancies and current or previous molar pregnancy. Other risk factors for hyperemesis include maternal age, genetic susceptibility, parity, ethnicity, marital status, smoking, unplanned pregnancies, depression or psychiatric illness, less socioeconomic status, previous history of hyperemesis, preexisting diabetes, body mass index, asthma, hyperthyroid disorders, female fetus, dysmenorrhea, urinary tract infections, peptic ulceration and other gastrointestinal disorders (Dinberu, et al, 2019).

Hyperemesis gravidarum is a serious complication during pregnancy presenting as prolonged and severe nausea and vomiting causing dehydration, malnutrition and significant morbidity. Women with a history of HG have around an $80 \%$ chance of suffering in subsequent pregnancies. Careful and thorough planning in advance of future pregnancy can significantly reduce the overall severity of symptoms and improve the psychosocial welfare of the women as well as pregnancy outcomes. This article explores the various aspects of a thorough prophylactic care plan to optimize the outcomes of future pregnancies and reduce the morbidity associated with $\mathrm{HG}$ (Dean, et al, 2020).

Management of $\mathrm{HG}$ requires a combination of medical and nursing interventions, lifestyle changes, dietary changes, adjunctive care, and pregnant women education, which should be used early, because HG is more difficult and costly to manage over time. Proactive treatment may reduce symptom severity, thus treatment should begin at the onset of symptoms, limiting food and/or fluid intake. The primary nursing management goals are to reduce symptoms to improve maternal health and well-being, optimize maternal/fetal outcomes, and reduce costs. This requires a focus on maintaining hydration and nutrition but also mobility. Infusion nurses are key advocates for achieving these goals (Nurmi, et al, 2020).

In the early stages, many pregnant women with HG will be advised to rest, eat bite-size pieces of dry toast or crackers before getting out of bed, and have frequent, small meals. Fried or spicy foods, or smells that trigger symptoms of nausea and vomiting, are best avoided. Some women benefit from eating ginger or foods containing ginger, such as ginger biscuits and drinking ginger herbal tea. When symptoms are severe, admission to hospital may be needed for observation and to treat dehydration with intravenous fluids (Jasline, 2019).

\section{Significance of the study}

Hyperemesis gravidarum affects approximately $0.3 \%$ to $3.6 \%$ of pregnancies (MacGibbon, et al, 2021). According to (Mahmoud 2012) in Egypt, there was high prevalence of H.G which was $4.5 \%$ in relation to the universal prevalence. $\mathrm{HG}$ is serious conditions that lead to Wernicke's encephalopathy, severe electrolyte imbalance that can result in ventricular fibrillation and cardiac arrest, and pro-longed stress that can result in post-traumatic stress disorder (PTSD) (DSM-IV-R) following pregnancy (Kim, et al, 2021).

For offspring exposed in utero to HG, there is an increased risk of preterm birth, small for gestational age, low birth weight and necessity for neonatal care and/or resuscitation. Children are at an increased risk of 


\section{Asmaa Sobhi, Samia Abd-Elhakeem, Somaya Ouda and Ola Abd-Elwahab}

neurodevelopmental delay and autism spectrum disorder and may be at increased risk of reduced insulin sensitivity, higher blood pressure, increased fat mass and increased cortisol levels. Disease severity is often underestimated, resulting in increased maternal weight loss, which may contribute to these adverse maternal and offspring outcomes

(Poeran-Bahadoer, et al, 2020).

Improved Knowledge and practices may help pregnant women feel more empowered which in turn may reduce severity of $\mathrm{HG}$, the overall complications and quality of life consequences of HG (Mohamed and Hassan, 2019). So, our study aims to evaluate effectiveness of educational guidelines on women's knowledge and practices regarding hyperemesis gravidaurm.

\section{Aim of the study}

The current study aimed to assess knowledge and practices of pregnant women regarding hyperemesis gravidarum.

\section{Research questions:}

Q1: What is the level of pregnant women's knowledge regarding hyperemesis gravidaurm?

Q2: What is the level of pregnant women's practices regarding hyperemesis gravidaurm?

\section{Subjects and Method:}

\section{Research Design:}

A descriptive study design was used to fulfill this study.

\section{Study Setting:}

This study was conducted at Obstetrics and

Gynecological inpatient department and outpatient clinic at Benha University hospital.

\section{Sampling:}

A purposive sample was used 50 pregnant women suffer from hyperemesis gravidaurm were admitted to the previous setting for eight months fulfill the inclusion criteria:

- Pregnant women age between 19 and 35 years old.

- Pregnant women medically diagnosed with hyperemesis gravidaurm by physician.

- Pregnant women with HG and free from any psychological disorder.

\section{Tools of data collection:}

One tool utilized for collecting data:

A structured-interviewing questionnaire sheet:

It constructed by investigator after reviewing a related literature and translated into Arabic language. It consisted of three parts, part I: Socio-demographic data such as (age, residence, level of education, occupation and income).

\section{Part II: Knowledge assessment sheet:}

It was designed by investigator to assess pregnant women's knowledge about hyperemesis gravidarum. It consisted of 21 question of multi choice.

\section{Scoring system:}

All knowledge variables were weight according to items include in each question. The answer of the questions was classified into two categories. The answer would have score (1) for correct answer and score (0) for incorrect answer.

\section{Total knowledge score will classify as the}

\section{following:}

- Good: (> $75 \%$ correct answer).

- Average: (50 $\leq 75 \%$ correct answer).

- Poor: $(<50 \%$ correct answer).

Part III: Maternal health practices questionnaire:

It was designed by investigator to assess practices of pregnant women regarding HG. It consisted of 14 items. 


\section{Assessment of Knowledge and Practices of Pregnant Women regarding Hyperemesis Gravidarum}

\section{Scoring system: -}

The score of practices range from $(0)$ to (2), each statement scores as following: (2) if always done, (1) if sometimes done and (0) if never done.

Total practices score will classify into two levels:

- Satisfactory level: $\geq 60 \%$.

- Unsatisfactory level: $<60 \%$.

\section{Tools validity:}

The validity of questionnaire was reviewed by " 3 " jury to three experts in the field of Obstetrics \& Gynecological health nursing at faculty of Benha University to ascertain clarity, relevance, comprehensiveness and applicability of tools. Modifications were done such as adding, rephrasing and omitting some questions.

\section{Reliability:}

Reliability of the tool was measured by using Cronbach's Alpha test, to measure internal consistency of the study result. Cronbach's Alpha coefficient of knowledge questionnaire was $(0.76 \%)$.

\section{Ethical consideration:}

- The study approval was obtained from Scientific Research Ethical Committee of faculty of nursing at Benha University before starting the study.

- An official permission from the selected study setting was obtained for the fulfillment of the study.

- Before applying the tools, the researcher explained the aim and importance of the study to gain women's confidence and trust.

- The researcher took oral consent from women to participate in the study and confidentialities were assured.

- The data was collected and treated confidentially, where personal data were not disclosed and the women were assured that all data was used only for research purpose.

- The women were free to withdraw from study at any time.

- The study didn't have any physical, social or psychological risk on the participants.

\section{Pilot study:}

The pilot study was conducted on $10 \%$ from total period eight months (32 weeks) approximately 3 weeks (three days per weeks) to test the clarity and applicability of the tools. Modifications had done according to the pilot results and pilot sample had excluded from the study.

\section{Field work:}

The study was carried out from the beginning of March 2020 to the end of April 2020, then from beginning of July to the end of December 2020, covering eight months. The researcher attended the pre mentioned setting from $9 \mathrm{Am}$ to $12 \mathrm{pm}$, three days per week (Saturdays, Mondays and Wednesdays) until the predetermined duration was completed. The researcher had prolonged the duration of data collection to able to collect acceptable sample size because a lot of hospitals was transformed to isolation hospital due to breakout covid-19.

\section{Statistical analysis:}

The collected data were organized, tabulated and statistically analyzed using SPSS software statistical computer package version 25 and the study sample was calculated using the Ep-iinfo program. For quantitative data, the range, mean and standard deviation were calculated. For qualitative data, comparison was done using Chi-square test $(\chi 2)$. Correlation between variables was evaluated using Pearson and Spearman's correlation coefficient r. A significance was adopted at 


\section{Asmaa Sobhi, Samia Abd-Elhakeem, Somaya Ouda and Ola Abd-Elwahab}

$\mathrm{P}<0.05$ for interpretation of results of tests of significance $(*)$. Also, a highly significance was adopted at $\mathrm{P}<0.01$ for interpretation of results of tests of significance $(* *)$.

\section{Results:}

Table (1): Shows that more than twothirds $(70.0 \%)$ of studied sample were in age group 19 - 23 years with a mean age of $22.56 \pm 3.24$ years. As regards the residence, less than two-thirds $(60.0 \%)$ of them lived in rural areas. Furthermore, more than three-quarters of them $(78.0 \%)$ were housewives. Regarding the educational level, more than half $(58.0 \%)$ of them had secondary education. Moreover; more than half $(54.0 \%)$ of them had fairly sufficient income.

Table (2): Reveals that more than half (52.0) of studied women had (correct answer) about the severe complications that may occur as a result of H.G, while the majority (86.0) of them had (incorrect answers) about cases of $\mathrm{HG}$ in which doctor is forced to terminate a pregnancy.

Table (3): Illustrates that there was twofifth of mothers $(40.0 \%)$ always drinking more fluids to prevent dehydration, at least 2 liters per day. while the majority (80.0) and more than three-quarters of them (76.0) never sleeping enough hours every day \& sleeping early and sleeping in a dark and quiet room to avoid sensory stimulation respectively. the current study findings clarified that less than one-third of studied sample had satisfactory level of practices regarding hyperemesis gravidarum. While, it was revealed that less than three-quarter of studied sample had unsatisfactory level of practices regarding hyperemesis gravidarum.

Table (4): Clarifies that; there was a highly positive statistical correlation between total knowledge and total practices regarding hyperemesis gravidaurm $(\mathrm{P} \leq 0.001)$.

Table (1): Socio-demographic data of the studied women $(n=50)$.

\begin{tabular}{|l|c|c|}
\hline \multicolumn{1}{|c|}{ General characteristics } & No & $\%$ \\
\hline Age & 35 & 70.0 \\
\hline $19-23$ & 12 & 24.0 \\
\hline $24-29$ & 3 & 6.0 \\
\hline $30-35$ & \multicolumn{2}{|c|}{} \\
\hline \multicolumn{3}{|c|}{ Rean \pm SD $=22.56 \pm 3.24$} \\
\hline Rural & 30 & 60.0 \\
\hline Urbance & 20 & 40.0 \\
\hline Level of education & 2 & 4.0 \\
\hline Illiterate & 7 & 14.0 \\
\hline Basic education & 29 & 58.0 \\
\hline Secondary education & 12 & 24.0 \\
\hline University education & 39 & 78.0 \\
\hline Occupation & 11 & 22.0 \\
\hline Housewife & 11 & 22.0 \\
\hline Employed & 27 & 54.0 \\
\hline Income & 12 & 24.0 \\
\hline Enough
\end{tabular}


Table (2): Frequency Distribution of studied sample regarding their knowledge about hyperemesis gravidarum $(\mathbf{n}=\mathbf{5 0})$.

\begin{tabular}{|c|c|c|c|c|}
\hline \multirow{2}{*}{ Knowledge items } & \multicolumn{2}{|c|}{ Correct } & \multicolumn{2}{|c|}{ Incorrect } \\
\hline & No & $\%$ & $\overline{\text { No }}$ & $\%$ \\
\hline Definition of hyperemesis gravidarum & 12 & 24.0 & 38 & 76.0 \\
\hline $\begin{array}{l}\text { The difference between normal morning sickness and hyperemesis } \\
\text { gravidarum }\end{array}$ & 14 & 28.0 & 36 & 72.0 \\
\hline The times of day at which HG occurs & 11 & 22.0 & 39 & 78.0 \\
\hline Gestational age in weeks of at which HG occurs & 12 & 24.0 & 38 & 76.0 \\
\hline Risk factors of $\mathrm{HG}$ & 9 & 18.0 & 41 & 82.0 \\
\hline Signs and symptoms of $\mathrm{HG}$ & 20 & 40.0 & 30 & 60.0 \\
\hline Noticeable signs at clinical examination & 13 & 26.0 & 37 & 74.0 \\
\hline Biochemical changes that occur due to $\mathrm{HG}$ & 10 & 20.0 & 40 & 80.0 \\
\hline Causes related to pregnancy and may lead to HG & 18 & 36.0 & 32 & 64.0 \\
\hline Causes that are not related to pregnancy and may lead to HG & 15 & 30.0 & 35 & 70.0 \\
\hline Complications of $\mathrm{HG}$ for the mother & 23 & 46.0 & 27 & 54.0 \\
\hline Complications of HG for the fetus & 20 & 40.0 & 30 & 60.0 \\
\hline Severe complications that may occur as a result of $\mathrm{HG}$ & 26 & 52.0 & 24 & 48.0 \\
\hline Diagnosis of HG & 17 & 34.0 & 33 & 66.0 \\
\hline Investigation should be performed for a woman suffering from $\mathrm{HG}$ & 10 & 20.0 & 40 & 80.0 \\
\hline Prevention methods of $\mathrm{HG}$ & 14 & 28.0 & 36 & 72.0 \\
\hline Healthcare modalities for $\mathrm{HG}$ & 8 & 16.0 & 42 & 84.0 \\
\hline Observations in case of hospitalization & 16 & 32.0 & 34 & 68.0 \\
\hline Effective nutritional recommendations in health care for HG & 18 & 36.0 & 32 & 64.0 \\
\hline Alternative treatments used to reduce the frequency of vomiting & 10 & 20.0 & 40 & 80.0 \\
\hline Prohibited foods in case of $\mathrm{HG}$ & 13 & 26.0 & 37 & 74.0 \\
\hline Cases of HG in which doctor is forced to terminate a pregnancy & 7 & 14.0 & 43 & 86.0 \\
\hline
\end{tabular}

*A Statistical significant $\mathbf{p} \leq \mathbf{0 . 0 5}$.

$* *$ A Highly Statistical significant $\mathbf{p} \leq \mathbf{0 . 0 0 1}$.

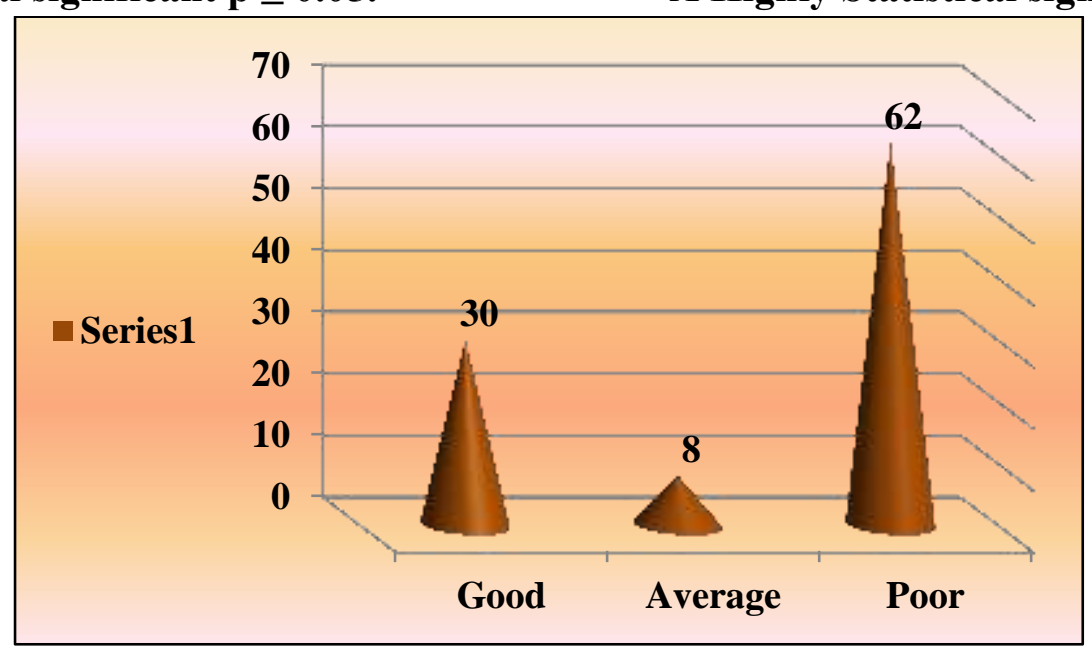

Figure (1): Frequency Distribution of studied sample regarding their total knowledge score about hyperemesis gravidarum $(n=50)$. 


\section{Asmaa Sobhi, Samia Abd-Elhakeem, Somaya Ouda and Ola Abd-Elwahab}

Table (3): Frequency Distribution of studied sample regarding their practices related to hyperemesis gravidarum $(\mathbf{n}=\mathbf{5 0})$

\begin{tabular}{|c|c|c|c|c|c|c|}
\hline \multirow{2}{*}{ Practices items } & \multicolumn{2}{|c|}{ Always } & \multicolumn{2}{|c|}{$\begin{array}{l}\text { Sometime } \\
\mathrm{s}\end{array}$} & \multicolumn{2}{|c|}{ Never } \\
\hline & No & $\%$ & No & $\%$ & No & $\%$ \\
\hline $\begin{array}{l}\text { Following the schedule of antenatal visits as a risk } \\
\text { pregnancy, according to the doctor's instructions. }\end{array}$ & 19 & 38.0 & 2 & 4.0 & 29 & 58.0 \\
\hline Taking nutritional supplements prescribed by a doctor. & 17 & 34.0 & 1 & 2.0 & 32 & 64.0 \\
\hline Taking the medicine at the prescribed time as recommended. & 11 & 22.0 & 3 & 6.0 & 36 & 72.0 \\
\hline Sleeping enough hours every day and sleeping early. & 8 & 16.0 & 2 & 4.0 & 40 & 80.0 \\
\hline Sleeping in dark and quiet room to avoid sensory stimulation. & 8 & 16.0 & 4 & 8.0 & 38 & 76.0 \\
\hline Tracking the weight regularly. & 15 & 30.0 & 2 & 4.0 & 33 & 66.0 \\
\hline $\begin{array}{l}\text { Getting rest after eating for some time at least a quarter of an } \\
\text { hour to help prevent stomach muscles from cramping and } \\
\text { vomiting. }\end{array}$ & 15 & 30.0 & 5 & $\begin{array}{c}10 . \\
0\end{array}$ & 30 & 60.0 \\
\hline Avoid using perfumes and stimuli. & 18 & 36.0 & 3 & 6.0 & 29 & 58.0 \\
\hline $\begin{array}{l}\text { Eat small and frequent meals that are high in carbohydrates } \\
\text { and low in protein in fat. }\end{array}$ & 11 & 22.0 & 2 & 4.0 & 37 & 74.0 \\
\hline $\begin{array}{l}\text { Eat dry biscuits first when waking up in the morning before } \\
\text { getting out of bed. }\end{array}$ & 17 & 34.0 & 1 & 2.0 & 32 & 64.0 \\
\hline Eat snacks before bed to reduce the urge to vomit. & 14 & 28.0 & 1 & 2.0 & 35 & 70.0 \\
\hline $\begin{array}{l}\text { Eat bananas regularly to supply the body with mineral salts } \\
\text { that help reduce nausea and vomiting. }\end{array}$ & 10 & 20.0 & 3 & 6.0 & 37 & 74.0 \\
\hline Drinking a glass of milk before bed. & 19 & 38.0 & 4 & 8.0 & 27 & 54.0 \\
\hline $\begin{array}{l}\text { Drinking more fluids to prevent dehydration, at least } 2 \text { liters } \\
\text { per day. }\end{array}$ & 20 & 40.0 & 5 & $\begin{array}{c}10 . \\
0\end{array}$ & 25 & 60.0 \\
\hline
\end{tabular}

*A Statistical significant $\mathbf{p} \leq \mathbf{0 . 0 5}$.

**A Highly Statistical significant $\mathbf{p} \leq \mathbf{0 . 0 0 1}$.

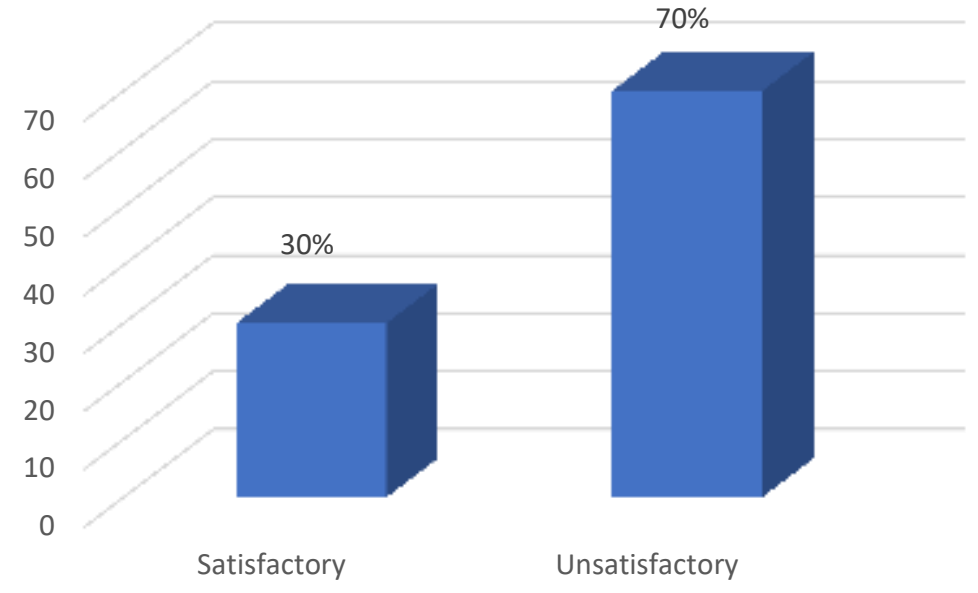

Figure (2): Frequency Distribution of studied sample regarding their total practices score about hyperemesis gravidarum $(n=50)$. 
Table (4): Correlation between total knowledge and total healthy practices score of the studied sample regarding hyperemesis gravidaurm $(n=50)$.

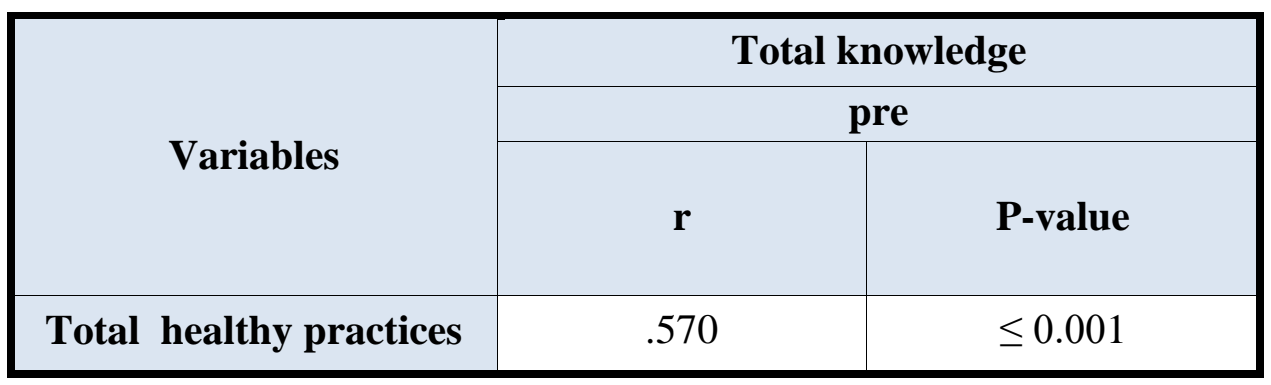

$* *$ A Highly Statistical significant $\mathbf{p} \leq \mathbf{0 . 0 0 1}$

\section{Discussion}

Hyperemesis Gravidarum is considered the most severe manifestation of nausea and vomiting during pregnancy and presented in $0.3-3 \%$ of all pregnancies. Despite an apparently relatively low incidence, $\mathrm{HG}$ represents the most common cause of hospitalization during the first half of pregnancy. Its complications include weight loss, dehydration, electrolyte disturbances, and nutritional deficiency. Also, HG has been associated with premature delivery and small gestational-age infants. Moreover, recurrence in consecutive pregnancies is high where ranging from $15 \%$ to more than $80 \%$ (Havnen, et al, 2019).

Pregnant women's empowerment with knowledge allows them to identify and express their health needs, encourage them to ask for treatment and support without hesitation and improve their practices and make effective decisions about their own health. Failure to provide awareness leaves women in the dark and establishes a gap between pregnant women and health care providers (Zaki, et al, 2021).

This study aimed to evaluate effectiveness of educational guidelines on women's knowledge and practices regarding hyperemesis gravidaurm.

\begin{abstract}
General characteristics of studied sample such as age, residence, educational level, occupation and income mainly affect women's knowledge and practices regarding hyperemesis gravidaurm. So, these factors should be determined for the studied sample. The finding of the current study revealed that more than two-thirds of studied sample were in age group 19 - 23 years with a mean age of 22.56 \pm 3.24 years. As regards the residence, less than two-thirds of them lived in rural areas. Furthermore, more than three-quarters of them were housewives. Regarding the educational level, more than half of them had secondary education. Moreover, more than half of them had fairly sufficient income.
\end{abstract}

This result was consistent with (Kamali, et al, 2018) who conducted "The effect of small group teaching on quality of life in pregnant women with nausea and vomiting" found that mean age of woman was $24.4 \pm 4.6$ years. Also, (Thakur, et al, 2019) who studied "Severity of hyperemesis gravidarum and associated maternal factors" documented that more than half of women were in age group 1924 years. Additionally, (Hassan, et al, 2019) who studied "Nursing role in application off nutritional guidelines during hyperemesis 


\section{Asmaa Sobhi, Samia Abd-Elhakeem, Somaya Ouda and Ola Abd-Elwahab}

gravidarum and its effect on patients outcomes" cleared that most of women were from rural areas.

In the same context (Muwonge, 2019) who studied that "Risk factors for hyperemesis gravidarum among pregnant women attending antenatal clinic at kawempe hospital" reported that majority of women had at least secondary education. Also, (Hassan, et al, 2019) documented that about three fifths of women were housewives.

Moreover, these results agreed with (Ali and Abokresha, 2021) who studied that "Patterns and determinants of utilization of antenatal care services by pregnant women in Sohag, Upper Egypt" mentioned that more than half of women were from rural areas. Also, (Ali and Abokresha, 2021) reported that the families of more than three fifths of women had satisfactory income. This similarity in results may be related to the similarities of community features and convergence in sample size.

On the other hand, this result was on the contrary with (Akhtar, et al, 2018) who studied "Knowledge, attitude and practice regarding antenatal care among pregnant women in rural area of lahore" indicated that about half of pregnant women were in age above 30 years old. Also, (Ali and Abokresha, 2021) who showed that mean age of pregnant women was $30.4 \pm 3.8$.

Additionally, in contrast to this study (Mekonnen, et al, 2018) who studied "Risk factors of hyperemesis gravidarum among pregnant women in bale zone hospitals, southeast Ethiopia", found that more than two thirds of subjects were from urban areas. While, (Farg and Hassan, 2019) who studied "Study hyperemesis gravidarum requiring hospital admission during pregnancy: effect of nursing implication on its progress" cleared that about one third of subjects had basic education and more than one quarter of them were illiterate.

Furthermore, (Dean and Marsden, 2017) contradicted this study in his study entitled "Satisfaction for treatment of hyperemesis gravidarum in day care settings compared to hospital admissions" who found that about three quarters of women were employed. In addition to, (Farg and Hassan, 2019) who illustrated that more than half of subjects had insufficient income. This congruence can be explained by convergence in residence of studied subjects live in urban area more than subject in our research and their level of education was higher.

Knowledge is a vital element to enable women to be aware of their health status during their pregnancies. However, studies have shown that many women either lack knowledge or show a lack of concern for certain health risks in pregnancy, This indicates that there is the need for a more effective drive to educate women and help them to acquire appropriate knowledge to acquire proper skills towards a healthy practices during pregnancy (Mohamed and Hassan, 2019).

Owing to knowledge of the studied women regarding hyperemesis gravidarum, the current study findings clarified that, more than half (52.0) of studied women had (correct answer) about the severe complications that may occur as a result of H.G, while the majority (86.0) of them had (incorrect answers) about cases of HG in which doctor is forced to terminate a pregnancy. The current study findings clarified that there was less than twothirds of the studied women had poor knowledge regarding hyperemesis gravidarum; while less than one-third of them had good knowledge. 


\section{Assessment of Knowledge and Practices of Pregnant Women regarding Hyperemesis Gravidarum}

This result went in the same line with (Samarakoon, et al, 2020) who studied "Knowledge and Practices Regarding SelfManagement of nausea and vomiting among Pregnant Mothers" reported that most of the participants were experienced nausea and vomiting and majority of them (94.1\%) had poor knowledge level regarding these symptoms.

This result was consistent with (Kaur and Gagandeep, 2017) who studied" Assessment of nausea and vomiting of pregnancy on antenatal clients of Addis Ababa" cleared that majority $(76 \%)$ of antenatal mothers had average knowledge regarding major ailments of pregnancy whereas, (22\%) antenatal mothers had poor knowledge and very few (2\%) had good knowledge regarding major ailments of pregnancy.

The result of our study matched with (Jasline, 2019) who applied that "A Study to Assess the Effectiveness of self-Instructional Module on Knowledge Regarding Home Care Management of Hyperemesis Gravidarum among Primi Gravida Mothers in a Selected Community Areas in Dehradun, India" signifies that $(82 \%)$ of mothers had inadequate knowledge, (18\%) had moderate knowledge and none of them had adequate knowledge.

This result was in agreement with (Sharma, et al, 2020) who studied" Knowledge and practices regarding management of major ailments of pregnancy among antenatal mothers: a descriptive study from Rajasthan" found that almost $(61 \%)$ of antenatal mothers had fair knowledge followed by (37\%) had poor knowledge and only (2.4\%) women reported to have good knowledge.

Additionally, the result of our study matched with (Nadia, et al, 2009) who studied "Assessment of knowledge and practice of women toward minor discomforts during the period of pregnancy" indicated that $40 \%$ of sample had poor knowledge at 1st trimester while $42 \%$ of sample had good knowledge at 2nd trimester followed by 3rd trimester.

In the same context, (Kamali, et al, 2018) who conducted "The effect of small group teaching on quality of life in pregnant women with nausea and vomiting" found that total knowledge score in the intervention group had statistically significant difference before and after the teaching intervention. Also, (Farg and Hassan, 2019) who studied "Study hyperemesis gravidarum requiring hospital admission during pregnancy: effect of nursing implication on its progress" found that found that women with hyperemesis gravidarum achieved better score in their knowledge degree after implementing the educational program. This similarity in the result due to low level of education.

The researcher believes that, the defect of knowledge may be due to lack of educational programming that supported by booklets and posters. Therefore, it is necessary to apply and design educational programs to raise awareness among pregnant women regarding hyperemesis gravidarum.

Regarding practices of the studied women regarding hyperemesis gravidarum, the current study findings clarified that there was two-fifth of mothers (40.0\%) always drinking more fluids to prevent dehydration, at least 2 liters per day. while the majority (80.0) and more than three-quarters of them (76.0) never sleeping enough hours every day \& sleeping early and sleeping in a dark and quiet room to avoid sensory stimulation respectively. the current study findings clarified that less than one-third of studied sample had satisfactory level of practices regarding hyperemesis 


\section{Asmaa Sobhi, Samia Abd-Elhakeem, Somaya Ouda and Ola Abd-Elwahab}

gravidarum. While, it was revealed that less than three-quarter of studied sample had unsatisfactory level of practices regarding hyperemesis gravidarum.

The result of the current study was supported by (Zaki, et al, 2021) who studied "Assessment of knowledge and practices of pregnant women toward danger signs of pregnancy" reported that about two thirds of pregnant women had inadequate practice toward danger signs during pregnancy as hyperemesis gravidarum.

This result was agreement with (Anwar, et al, 2019) who studied "Guideline for Management of Hyperemesis Gravidarum" showed that highly statistically significant difference was found in life style modification regarding nutrition during the follow up from the initial observation to the nine one. This reflected upon the compliance of study subjects to the instructions and health teaching that were given.

Additionally, the result of our study matched with (Oliveira, et al, 2018) who applied "Effect of an educational intervention on pregnancy: a cluster-randomized clinical trial" indicated that the educational intervention was effective in improving the knowledge and practices of pregnant women.

Also, (Abd El haliem, et al, 2018) who studied "Utilization of self-care practice guideline on relieving nausea and vomiting among new pregnant woman" found that there was a highly statistical significant difference between pre-intervention phase and postintervention phase. The total practice improved after education intervention where most of subjects achieved satisfactory level of practice post intervention compared to less than one fifths pre interventions.
Moreover, (Teweldemedhin, et al, 2021) who conducted "Effect of nutrition education by health professionals on pregnancy-specific nutrition knowledge and healthy dietary practice among pregnant women in Asmara, Eritrea" found that the practice score post the educational intervention was significantly higher than that of preintervention. This result was in agreement with (Abu-Baker, et al, 2021) who found that the intervention group recorded significantly higher total practices score after implementation of the health education program.

On the other hand, this result was disagrees with (Sharma, et al, 2020) who cleared that majority $(86 \%)$ of mothers ate frequent meals followed by $(74 \%)$ of women avoid strong odors smell in order to manage nausea and vomiting. This result was inconsistent with (Akhtar, et al, 2018) who found that $(61 \%)$ participants have positive practices towards antenatal care.

Concerning the correlation between total knowledge and total healthy practices score of the studied sample, the current study findings clarified that there was a highly positive statistical correlation between total knowledge and total practices regarding hyperemesis gravidaurm.

This result was consistent with (Abd El haliem, et al, 2018) found that there was a highly positive association between knowledge improvement subsequently improves practice. Increasingly, (Tenaw, et al, 2018) documented that knowledge had a positive association with good practices of women during pregnancy.

This result was supported by (Zaki, et al, 2021) reported that an important association has been found between the overall knowledge score and the practices of pregnant women. In addition, (Havnen, et al, 2019) who studied 
"Women's perspectives on the management and consequences of hyperemesis gravidarum; a descriptive interview study" reported that improving knowledge is needed to improve healthy practices of women with HG. This finding supported the importance of the educational program and antenatal mother classes to improve knowledge and practices among pregnant women regarding HG. Finally, the finding of the current study were answered the study questions and achieved the aim of the study.

\section{Conclusion}

Less than two-thirds of the studied women had poor knowledge regarding hyperemesis gravidarum; while less than onethird of them had good knowledge. Regarding to healthy practices of mothers, less than threequarters of mothers had unsatisfactory healthy practices and less than one-third of them had satisfactory healthy practices. Additionally, there was a highly positive statistical correlation between total knowledge and total practices regarding hyperemesis gravidaurm $(\mathrm{P} \leq 0.001)$. Finally, the finding of the current study were answered the study questions and achieved the aim of the study.

\section{Recommendations}

- Designing, implementing and distributing guidelines for hyperemesis gravidarum through antenatal clinic during initial visit of the pregnant women.

- Increase awareness of pregnant women about hazards of nausea and vomiting during pregnancy and necessary of early seeking medical care to avoid deterioration of the case and developing to hyperemesis gravidarum.

- Designing and applying an educational nursing mother class for the health care provider about how to provide health education for pregnant women at different antenatal clinics and psychological support and reassurance for the women with hyperemesis gravidarum to cope safely with her pregnancy.

- Further studies are recommended to :

- Evaluate health team immediate intervention related to hyperemesis gravidaurm.

\section{References}

Abd El haliem, S., Abd El hady, R., and Mohamed, A. (2018). Utilization of self-care practice guideline on relieving Nausea and Vomiting among new pregnant woman. Journal of Nursing and Health Science; 7(1): 7-15.

Abu-Baker, N., Abusbaitan, H., Al-Ashram, S., and Alshraifeen, A. (2021). The Effect of Health Education on Dietary Knowledge and Practices of Pregnant Women in Jordan. International Journal of Women's Health; 13(4): 433-443.

Akhtar, S., Hussain, M., Majeed, I., and Afzal, M. (2018). Knowledge Attitude and Practice Regarding Antenatal Care among Pregnant Women in Rural Area of Lahore. International Journal of Social Sciences and Management;

5(3):155-162.

Ali, R. and Abokresha, A. (2021). Patterns and Determinants of Utilization of Antenatal Care Services by Pregnant Women in Sohag, Upper Egypt. Journal of High Institute of Public Health; 51(1): 33-38.

Anwar, A., Hassan, S., Abd El-fatah, H., and El-Nemer, A. (2019). Guideline for Management of Hyperemesis Gravidarum. IOSR Journal of Nursing and Health Science (IOSR-JNHS); 8 (1): 70-76.

Dean, C. and Marsden, J. (2017). Satisfaction for treatment of hyperemesis gravidarum in day care settings compared to hospital admissions, MIDIRS Midwifery Digest Journal; 27(1): 11-19. 


\section{Asmaa Sobhi, Samia Abd-Elhakeem, Somaya Ouda and Ola Abd-Elwahab}

Dean, C., Bruina, C., O'Harab, M., Rosebooma, T., Leeflangc, M., Spijkerc,d, R. and Painter, R. (2020). The chance of recurrence of hyperemesis gravidarum; a systematic review. European Journal of Obstetrics \& Gynecology and Reproductive Biolog; 5(20): 222-235.

Dinberu, M. T., Mohammed, M. A., Tekelab, T., Yimer, N. B., Desta, M., \& Habtewold, T. D. (2019): Burden, risk factors and outcomes of hyperemesis gravidarum in low-income and middle-income countries (LMICs): systematic review and meta-analysis protocol. BMJ open; 9(4): e025841.

Farg, D. and Hassan, H. (2019). Study Hyperemesis Graviderum Requiring Hospital Admission during Pregnancy: Effect of Nursing Implication on Its Progress, American Journal of Nursing Research; 7(3): 328-341.

Hassan, M., Mostafa, M. and Fouly, H. (2019). Nursing Role in Application off Nutritional Guidelines during Hyperemesis Gravid Arum and Its Effect on patients Outcomes. Assuit Scientific Nursing Journal; 7(17): 189-195.

Havnen, G., Truong, M., Do, M., Heitmann, K., Holst, L. and Nordeng, H. (2019). Women's perspectives on the management and consequences of hyperemesis gravidarum, Scandinavian Journal of Primary Health Care; 37(1): 30-40.

Jasline, M. M. (2019). A Study to Assess the Effectiveness of self Instructional Module on Knowledge Regarding Home Care Management of Hyperemesis Gravidarum among Primi Gravida Mothers in a Selected Community Areas in Dehradun, India ;3(3):108-120.

Kamali, Z., Abedian, Z., Mohammad, A. and Dehnavi, Z. (2018). The effect of small group teaching on quality of life in pregnant women with nausea and vomiting, Journal of Education and Health Promotion; 7(12): 150-164.

Kaur., A., and Gagandeep. (2017). Assessment of the Knowledge and Expressed Practices Regarding Self-Management of Major Ailments Among Antenatal Mothers. IOSR Journal of Nursing and Health Science; 6(1):4954.

Kim, H. Y., Cho, G. J., Kim, S. Y., Lee, K. M., Ahn, K. H., Han, S. W., ... \& Kim, S. C. (2021). Pre-Pregnancy Risk Factors for Severe Hyperemesis Gravidarum: Korean Population Based Cohort Study. Life; 11(1): 12.

Kloter E., Gerstenberg G., Berenyi T., Gollmer B., Fliiger C., Klein U.,..\& Wolf U. (2019). Treatment of hyperemesis gravidaurm with anthroposophic complex therapy in 3 case repots. Complementary therapies in medicine ;44:14-17.

MacGibbon, K. W., Kim, S., Mullin, P. M., \& Fejzo, M. S. (2021). HyperEmesis Level Prediction (HELP Score) Identifies Patients with Indicators of Severe Disease: a Validation Study. Geburtshilfe und Frauenheilkunde; 81(01): 90-98.

Mahmoud, G. (2012). Prevalence and risk factors of hyperemesis graviderum among Egyptian pregnant woman at the Woman's Health Center. The Medical Journal of Cairo University; 80(2).

Mekonnen, A., Amogne, F. and Kassahun, C. (2018). Risk Factors of hyperemesis gravidarum among pregnant Women in Bale Zone Hospitals, Southeast Ethiopia, Journal of Clinics in Mother and Child Health; 15(3).

Mohamed, W. and Hassan, H. (2019). Educational Program to Enhance Pregnant Women's Knowledge about Dental Care and Periodontitis Outcomes. ARC Journal of Nursing and Healthcare; 5(3): 32-33. 
Muwonge, C. (2019). Risk factors for hyperemesis gravidarum among pregnant women attending antenatal clinic at Kawempe Hospital; a case control study. Master Thesis Project, College of Health Sciences, Makerere University, Kampala, Uganda.

Nadia A, M., Nadia M, F., \& Amel A, H. (2009). Assessment of knowledge and practice of women toward maorj discomforts during the period of pregnancy. New Egyptian Journal of Medicine; 94-104.

Nurmi, M., Rautava, P., Gissler, M., Vahlberg, T., \& Polo-Kantola, P. (2020). Incidence and risk factors of hyperemesis gravidarum: A national register-based study in Finland, 2005-2017. Acta obstetricia et gynecologica Scandinavica; 99(8): 1003-1013.

Oliveira, S. C. D., Fernandes, A. F. C., Vasconcelos, E. M. R. D., Ximenes, L. B., Leal, L. P., Cavalcanti, A. M. T. S., \& Lopes, M. V. D. O. (2018). Effect of an educational intervention on pregnancy: a clusterrandomized clinical trial. Acta Paulista de Enfermagem; 31(3): 291-298.

Poeran-Bahadoer, S., Jaddoe, V. W., Gishti, O., Grooten, I. J., Franco, O. H., Hofman, A., ... \& Gaillard, R. (2020). Maternal vomiting during early pregnancy and cardiovascular risk factors at school age: the Generation R Study. Journal of developmental origins of health and disease; 11(2): 118-126.

Samarakoon, S., Mohamed, F., Wijerathna, K. and Kisokanth, G. (2020): Knowledge and Practices Regarding Self- Management of
Nausea and Vomiting among Pregnant Mothers, Journal of Maternal and Child Health; 5(3): 303-312.

Sharma, A., Rani, R., Nebhinani, M., \& Singh, P. (2020). Knowledge and practices regarding management of minor ailments of pregnancy among antenatal mothers: a descriptive study from Rajasthan. International Journal of Community Medicine and Public Health; 7(10): 4010.

Tenaw, Z., Arega, A. and Tachbele, E. (2018). Nutritional knowledge, attitude and practices among pregnant women who attend antenatal care at public hospitals of Addis Ababa, Ethiopia. International Journal of Nursing and Midwifery; 10(7): 81-89.

Teweldemedhin, L., Amanuel, H., Berhe, S., Gebreyohans, G., Tsige, Z. and Habte, E. (2021). Effect of nutrition education by health professionals on pregnancy-specific nutrition knowledge and healthy dietary practice among pregnant women in Asmara, Eritrea, BMJ Nutrition, Prevention \& Health; 4(1): 181-194.

Thakur, M., Gautam, J. and Dangal, G. (2019). Severity of Hyperemesis Gravidarum and Associated Maternal factors, Journal of Nepal Health Research Council; 2(44): 293296.

Zaki, A., Fouad, S. and khedr, N. (2021). Assessment of knowledge and practices of pregnant women toward danger signs of pregnancy. Mansoura Nursing Journal; 8(1): 13-32. 


\section{معلومات وممارسات السيدات الحوامل فيما يتعلق بقيء الحمل المستعصي}

أسماء صبحي أحمد العباسي - سامية عبد الحكيم حسانين- سميه عوده عبد المنعم - علا عبد الوهاب عفيفي

قيء الحمل المستعصي هو مشكلة صحية قد تهدد حياة المرأة الحامل، يتميز بالغثيان الثديد والقيء المستمر ، ويصيب ؟. • ب؟٪ من السيدات أثناء الحمل. السيدات اللاتي يعانين منه يفقدن أكثر من ه٪ من وزنهن أثناء الحمل. وتثمل الأعر اض المرتبطة بـيء الحمل المستعصي علي إرتفاع معدل النبض، والإفر اط في إفراز اللعاب وسر عة ضربات القلب وصدور رائحة مصحوبة بالنفس (رائحة كيتونية). يؤدي قيء الحمل المستعصي إلى الجفاف، ونقص التغذية، وزيادة الكيتون في البول، وقلة في السوائل والأملاح، وعدم توازن الحمض القاعدي، وفي الحالات الثديدة قد يؤدي إلى تلف الكبد والكلى و الوفاة. لذا هدفت الدراسة الحالية إلى تقييم معلومات وممارسات السيدات الحوامل فيما يتعلق بقيء الحمل المستعصي. وقد أجريت هذه الدراسة في قسم أمر اض النساء و التوليد والعيادات الخارجية بمستشفى بنها الجامعي على •ـ سيدة. حيث اتضح من النتائج أن كان هنالك أقل من ثلثي السيدات الخاضعات للار اسة لديهن القليل من المعلومات عن قيء الحمل المستعصي. فيما يتعلق بالممارسات الصحية للسيدات الحوامل الخاضعات للار اسة كان هناك أقل من ثلاثة أرباع السيدات لايهن ممارسات صحية غير مرضية و أقل من ثلثهن كان لديهن ممارسات صحية مرضية فيما يتعلق بقيء الحمل المستعصي. بالإضافة إلى ذللك، كان هناك ارتباط إحصائي إيجابي للغاية بين المعرفة الكلية و الممارسات الكلية فيما يتعلق بقيء الحمل المستعصي. و أخير ا قد أجابت نتائج الدراسة الحالية على أسئلة الدراسة وحققت الهدف منها. وأوصت الدر اسة إلي زيادة الوعي العام المستهدف و البرامج التعليمية للسيدات الحوامل لتحسين مستوي الوعي فيما يتعلق بقيء الحمل المستعصي. 